A group of papers was devoted to the discussion of resonance phenomena. Here one is concerned primarily with the rapid oscillation of electrons between different positions in the molecule, and not with the movements of nuclei as in the free rotation problem. The problem of the structure of the organic azides was discussed by Sidgwick. The azide ion has undoubtedly the linear structure $\mathrm{N} \leftrightarrows \mathrm{N} \rightrightarrows \mathrm{N}$; for the covalent organic azides three structures are possible as shown below. Parachor and volatility favour I, whilst chemical reactions, electron diffraction, and recent crystal structure measurements reported by Bernal indicate a linear structure, II or III. The dipole moments of a number of azides give for the moment of the $\mathrm{Ph}-\mathrm{N}_{3}$ group about $1 \cdot 5 \mathrm{D}$. This is scarcely larger than the moment of the $\mathrm{Ph}-\mathrm{N}$ group, so that the links in the $\mathrm{N}_{3}$ group contribute very little to the moment. II and III should give

$$
R-N \|_{N}^{N} \underset{I I}{\longrightarrow}
$$$$
\begin{gathered}
\mathrm{R}-\mathrm{N} \leftarrow \mathrm{N} \equiv \mathrm{N} \\
\leftarrow
\end{gathered}
$$

III

large contributions in the senses indicated by the arrows below the formulæ, so the dipole moments seem to favour structure I. This is, however, quite incompatible with the electron diffraction and crystal measurements.

The low moment cannot be reconciled with a linear arrangement of the nitrogen atoms by postulating tautomerism in the chemical sense of the word between forms II and III. If the time of interchange between the two forms is less than the relaxation time $\left(c .10^{-12} \mathrm{sec}\right.$.), then each form would orient under the influence of the applied field and the observed moment would be large, although the two forms have moments of opposite sign. Quantum mechanical resonance between the two forms with an interchange time of the order of $10^{-15} \mathrm{sec}$. would account for the observed moment. For this to occur it is necessary for the two forms to have equal or nearly energies. Sidgwick has computed the heats of formation of the $\mathrm{N}_{3}$ group making certain plausible assumptions with the following results :

$$
\text { I, } 170 \mathrm{k} \text {. cal. II, } 191 \mathrm{k} \text {. cal. III, } 180 \mathrm{k} \text {. cal. }
$$

The observed value calculated from the heats of combustion of organic azides is $211 \mathrm{k}$. cal. This seems to exclude $\mathbf{I}$ and is compatible with resonance between II and III, since resonance increases the stability of the molecule and would increase the heat of formation.

The vector addition of dipole moments and the calculation of valency angles were considered in another group of papers. The chief difficulty met with in this field is the uncertain magnitude of the interaction between two dipoles in a molecule or between a dipole and the polarisable part of the same molecule. Hampson described a method of eliminating such errors considering the moments of a series of compounds, for example :
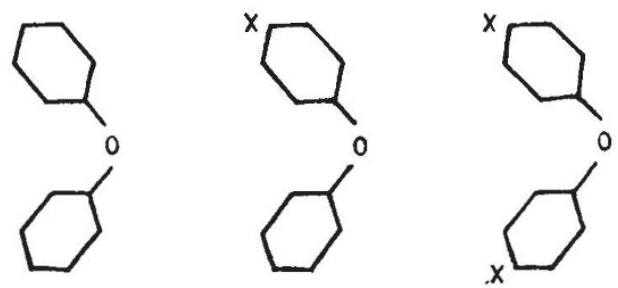

where $\mathrm{X}$ is a group of known moment. From the three measured moments it is possible to fix upper and lower limits for the valency angle and to estimate the magnitude of the perturbing induced dipole along the $\mathrm{X}-\mathrm{O}$ axis. For the oxygen valency angle consistent values of about $130^{\circ}$ were found; the induced dipole was small when $\mathrm{X}$ was $\mathrm{Cl}$ but when $\mathrm{X}$ was $\mathrm{NO}_{2}$ amounted to half a Debye unit.

Finally, mention must be made of the remarkable results found by Hassel for certain cyclohexane derivatives. $1: 4$ dichloro-, dibromo-, and di-iodo cyclohexane were found to have zero moment in solution in benzene. This result is not easily reconciled with the usual view that cyclohexane derivatives consist of a tautomeric mixture of two strainless forms with a non-planar configuration.

S. S.

\title{
University Statistics of Great Britain
}

$\mathrm{U}^{\mathrm{N}}$ NIVERSITY statistics of Great Britain for the year 1932-33, recently issued by the University Grants Committee*, show that the attendance of students has been well maintained and university finances have a healthy appearance. It would seem that the measures taken to temper the effect on universities in Great Britain of the inclement economic weather prevailing in the past few years have achieved their object. The enrolment of full-time students has been gradually rising since 1924-25 and showed last year a further increase of $1,255-1,267$ more men and 12 fewer women. of the aggregate total of 50,155 , five per cent were engaged in research and other advanced work, seventy-seven per cent were reading for a first degree and eighteen per cent for a diploma. Part-time students numbered 13,960 , of whom rather more than

* University Grants Committee. Returns from Universities and University Colleges in receipt of Treasury Grant, Academic Year 1932-33. Pp. 26. (London: H.M. Stationery Office, 1934.) 18. $3 d$. net. half were not pursuing regular courses leading to a degree or diploma.

A regional distribution of the full-time students gives to: London, 24 per cent ; Oxford and Cambridge, 21 per cent; provincial universities of the Midlands and northern England, $21 \frac{1}{2}$ per cent; Reading, Southampton, Exeter and Bristol, 5 per cent; Wales, 62 $\frac{2}{3}$ per cent; and Scotland, 22 per cent.

Students from abroad, that is, from homes outside the British Isles, numbered 5,870-about one tenth of the total number-considerably more than half of them being from countries within the British Empire: these show, however, a tendency to decrease in proportion to those from foreign countries. The following table gives particulars in respect of universities where such visitors from abroad were most numerous, showing (1) full-time students from places outside the British Isles but within the Empire, (2) those from foreign countries, and (3) the 
percentage of (1) plus (2) to the total number of students :

\begin{tabular}{|c|c|c|c|c|}
\hline & & $\begin{array}{c}\text { Students } \\
\text { (1) }\end{array}$ & $\begin{array}{r}\text { from abroad } \\
(2)\end{array}$ & $\begin{array}{c}\text { (Per cent) } \\
(3)\end{array}$ \\
\hline London . . & & 1,191 & 674 & 16 \\
\hline Sch. of Eco & aies & 141 & 234 & 39 \\
\hline Imperial Co & & 163 & 50 & 20 \\
\hline University & & 221 & 118 & 17 \\
\hline Guy's Hosp & & 99 & 18 & 14 \\
\hline St. Bart.'s & spl. & 78 & 34 & 15 \\
\hline Oxford $\quad \ldots$ & $\ldots$ & 290 & 234 & 11 \\
\hline Cambridge & . & 346 & 192 & 9 \\
\hline Birmingham & . & 28 & 85 & 11 \\
\hline Edinburgh & $\ldots$ & 329 & 176 & 14 \\
\hline St. Andrews & $\ldots$ & 14 & 87 & 11 \\
\hline
\end{tabular}

In view of current controversies and world-wide perplexity in regard to economic doctrine, it is noteworthy that the London School of Economics draws so many students from abroad.

Analysis according to subjects of study reveals a substantial increase of 807 (eight per cent) in the number of medical students and a falling off of five per cent under agriculture.

University finances, which are to a large extent dominated by State aid-parliamentary and local authorities' grants together amounting to $44 \frac{1}{2}$ per cent of the aggregate of university incomes-have called for close and unremitting attention on the part of university administrative authorities since the national financial crisis of 1931. Evidence of the effectiveness of their control is to be found in the fact that there were only four institutions the accounts of which showed deficits on the year and in only one was the deficit of any substantial amount. The aggregate amount of debt on capital account at the close of the year was about one million pounds, or one sixth of the aggregate annual income.

Expenditure on libraries is dissected in a special table which shows that of the total, $£ 210,756$, sixteen per cent was on account of purchase of periodicals, the increasing number and cost of which was already, three years ago, when they were responsible for little more than ten per cent of library expenditure, a source of embarrassment.

Four London institutions now make their first appearance in the returns: the Courtauld Institute of Art, first opened in October, 1932 ; the Institute of Education (formerly the London Day Training College), transferred from the control of the London County Council to that of the University of London in September, 1932; the Institute of Historical Research, statisties of which were previously not differentiated in the returns from those of the University of London as a whole; and the School of Slavonic and East European Studies, transferred from King's College to the University of London in August 1932.

\section{Quantitative Methods of Biological Assay}

$\mathrm{T}$ HERAPEUTIC substances, which cannot yet be completely defined by their physical and chemical characteristics, can only be used with safety when their activity has been determined by tests on animals. The accuracy of such tests has been greatly increased during the last decade, especially since it was realised that large numbers of animals must be used in each assay, so that the average response of a group of animals can be determined, allowance thus being made for the differences in response of the individual animals. Such tests may be of two types: either the response of each animal to the drug is accurately measured, for example, the effect of insulin upon the blood sugar of the rabbit; or observation is only made as to whether some specific effect is produced or not, for example, the effect of insulin upon the mouse, when the end-point is the occurrence, or not, of convulsions. Gaddum has recently made an analysis of the latter type of test and his report should be of great value in the interpretation of the results of such experiments.*

In tests of the 'all-or-none' or 'quantal' type, it is now usual to inject several doses of the substance under test into a series of animals, ten or twenty or more being used for each dose, and to plot the percentage number responding on each dose against the dose given. The curve which is then drawn to pass approximately through the plotted points is $S$-shaped, the shape and slope of the curve being characteristic for each combination of drug and test-animal species. It is often more convenient to plot the effect of the drug against the logarithm of the dose (to base 10) instead of against the dose itself ; the characteristic curves are then easier to interpret. The most satis-

* Reports on Biological Standards. (3) "Methods of Biological Assay depending on a Quantal Response." By J. H. Gaddum. Stationery Office, London, 1933.) 18. net. factory index of the slope of the curve, and so of the uniformity of the animals, is the standard deviation of the logarithms of the individual effective doses, which can be estimated with sufficient accuracy by taking from the curve the log-dose corresponding to 84 per cent, subtracting from it the log-dose corresponding to 16 per cent and halving the result.

Gaddum also recommends that instead of using the percentage of responses on each dose as a measure of the effect, the normal equivalent deviation be plotted against the logarithm of the dose, since this function gives a more satisfactory measure of the effect than the percentage does. It is equal to the deviation from the mean, and is obtained in practice from tables. When the normal equivalent deviations are plotted against the logarithms of the doses, the points so obtained lie approximately on straight lines, when the logarithms of the individual effective doses are normally distributed. It is therefore usually sufficient to use only two doses and to take the line joining them as an indication of the relation between the logarithm of the dose and the effect. This line is completely described by calculating the dose which produces the effect in half the animals and the standard deviation of the logarithms of the individual effective doses.

The report is illustrated by a number of curves obtained by different observers in assays of different drugs or hormones such as ouabain, neoarsphenamine, œstrin and pneumococcus antibody. The control of variables which affect the homogeneity of the animals used, such as their genetic composition, weight, age, sex, diet and environmental temperature, is also discussed. The mathematical argument involved in the use of these curves is described and, in greater detail, the methods of carrying out a test, two examples being included. 